\title{
Bersama elemen masyarakat menciptakan lingkungan sekolah yang kondusif untuk proses belajar mengajar
}

\section{Together with community elements creating a school environment that is conducive to the teaching and learning process}

\author{
Dody Fatkhur ${ }^{1}$, Y. Touvan Juni Samodra ${ }^{2}$ \\ ${ }^{1}$ SDN 11 Penyeberang Bala, Kecamatan Nanga Taman, Kabupaten Sekadau \\ ${ }^{2}$ Pendidikan Kepelatihan Olahraga, Universitas Tanjungpura \\ Email: dodyfatkhur46@gmail.com ${ }^{1}$, tovan@fkip.untan.ac.id. ${ }^{2}$
}

\section{INFO ARTIKEL}

Diterima : 10 Mei 2021

Disetujui : 25 Mei 2021

Tersedia secara Online Mei 2021

\author{
Alamat Korespondensi: \\ Dody Fatkhur \\ Penyeberang Bala, SENANGAK, Kec. \\ Nanga Taman, Kab. Sekadau Prov. \\ Kalimantan Barat \\ E-mail: dodyfatkhur46@gmail.com
}

\begin{abstract}
ABSTRAK
Dalam era modern seperti sekarang ini, kepala sekolah bukan hanya dituntut dapat menyelesaikan tugas-tugas dan masalah, tetapi juga dituntut untuk dapat mengembangkan potensi yang ada di sekolah menjadi sesuatu yang bermanfaat bagi peserta didik. Permasalahan yang terjadi di SDN 11 Penyeberang Bala saat ini yaitu masih banyaknya binatang ternak warga yang berkeliaran di lingkungan sekolah, sehingga mengganggu proses belajar mengajar di sekolah dan merusak tanaman yang ada di sekolah. Metode untuk mengatasi hal ini dengan membuat pagar sekolah, dengan melibatkan komite dan wali murid. Tujuan pembuatan pagar ini supaya binatang ternak tidak masuk ke lingkungan sekolah, sehingga lingkungan sekolah menjadi tempat yang nyaman untuk belajar. Berkat kerja sama seluruh warga sekolah, komite dan wali murid, akhirnya pagar sekolah dapat dibuat, dan peserta didik dapat belajar dengan nyaman.
\end{abstract}

\begin{abstract}
Kata Kunci: lingkungan sekolah, lingkungan belajar, sekolah.
In the modern era, the principal required to solve tasks and problems develops the existing potential in the school into something useful for students. The situation at SDN 11 Penyeberang Bala is that there is still much local livestock roaming around the school environment, thus disrupting the teaching and learning process and destroying existing plants in schools. The method to overcome this is by creating a school fence involving the committee and the guardians of the students. The purpose of making this fence is so that livestock does not enter the school environment so that the school environment becomes a comfortable place to study. Thanks to the cooperation of all school members, committees, and student guardians, finally, can create the school fence, and students can learn comfortably.
\end{abstract}

Keywords: school environment, learning environment, school

\section{PENDAHULUAN}

Lingkungan dalam artian abstrak dapat menjadikan pembelajaran karakter lebih baik (Rosyad, 2019). Lingkungan ini dapat lingkungan yang asri yang dapat dilihat dan dirasa, ataupun hubungan, suasana yang diciptakan untuk menggiring orang berperilaku yang didesain dalam tujuan pendidikan. Terdapat korelasi antara pengetahuan terhadap lingkungan dengan kesadaran terhadap lingkungan (Munawar, Heryanti, \& Miarsyah, 2019). 
Berdasarkan pada hal ini, di sekolah dasar merupakan tempat untuk mendidik dengan cara memberi contoh. Dengan melihat lingkungan yang ada, jika keadaan ini tidak sesuai dengan syarat lingkungan sekolah yang seharusnya, maka sebagai guru dan pimpinan sekolah harus memberikan contoh dengan berusaha untuk mengubah lingkungan menjadi lingkungan yang lebih kondusif.

Lingkungan sekolah memiliki sumbangan terhadap motivasi siswa dalam belajar (Nazir, 2019). Lingkungan sekolah dapat dipergunakan dalam pembelajaran, sebagai contoh pembelajaran ekosistem, dengan lingkungan sekolah yang mendukung dapat dipergunakan untuk proses pembelajaran (Anyau, 2018). Lingkungan sekolah dan keluarga yang butuh mempengaruhi terhadap kesulitan belajar (Wati \& Muhsin, 2019) (Aristha, 2019). Lingkungan dalam artian abstrak yang positif ternyata mendukung terhadap hasil belajar (Bryan Pudji Hartono, 2018).

Lingkungan sekolah mempengaruhi motivasi belajar dan secara bersama sama lingkungan sekolah dan motiviasi belajar berpengaruh terhadap hasil belajar siswa (Hsb, 2018). Bagaimana siswa berpersepsi terhadap lingkungan sekolah ternyata mempengaruhi hasil belajar (Herni, 2018). SDN 11 Penyeberang Bala adalah salah satu sekolah yang terletak di Desa Senangak, Kecamatan Nanga Taman, Kabupaten Sekadau, sekolah ini berjarak sekitar $85 \mathrm{Km}$ dari kota Sekadau, dan masuk dalam kategori sekolah terpencil.

Seperti umumnya sekolah di desa pelosok, sekolah ini mempunyai lahan yang cukup luas, lahan yang luas itu selama ini hanya di gunakan untuk mengikat ternak warga, baik berupa sapi atau kambing, bahkan babi pun masih berkeliaran di lingkungan sekolah. Hewanhewan ternak tersebut masuk ke lingkungan sekolah karena lingkungan sekolah tidak dipagar.

Lingkungan dapat berpengaruh terhadap siswa yang berada di dalamnya, sehingga sekolah harus menciptakan lingkungan agar belajar berlangsung dengan efektif Mashud, (2015) \& Fadhilaturrahmi, (2017). Lingkungan sekolah merupakan role model bagi siswa, lingkungan sekolah yang mengarah pada wira usaha ternyata memberikan minat positif untuk siswa termotivasi untuk berwirausaha (Aini, Santosa, \& Hamidi, 2017). Lingkungan sekolah yang positif juga akan meningkatkan nilai positif pada guru dan akhirnya berdampak pada kinerja (Suardi, Akib, \& Tamsah, 2016)

Lingkungan sekolah yang tidak sehat dan tidak bersih akan beresiko sebagai sumber penyakit. Maka penanganan terhadap lingkungan sekolah harus dilakukan dengan serius. Berdasarkan penelitian di Banyuwangi ternyata 100\% sekolah telah memenuhi indikator sebagai sekolah yang baik (Azizah, Puspikawati, \& Oktanova, 2019). Lingkungan yang seperti dalam penelitian ini yang di idam-idamkan. Kenyataan di lapangan di sekolah pelosok sekolah sangat tidak sehat bagi warga sekolah, khususnya peserta didik. Kotoran hewan di halaman sekolah menimbulkan aroma yang kurang sedap, ditambah lagi jika musim hujan tiba, anak-anak yang sebagian besar tidak memakai sepatu mudah sekali terkena penyait kulit karena menginjak kotoran hewan tersebut. Selain itu praktek pelajaran muatan lokal yaitu budidaya pertanian susah untuk terwujud karena tanaman yang ditanam dirusak oleh binatang.

Keyakinan penulis jika lingkungan sekolah ini diperbaiki maka akan memberikan manfaat yang sangat besar dalam proses pembelajaran ataupun motivasi, serta meningkatkan suasana belajar yang efektif. Penelitian berikut adalah sebagai argumentasi lingkungan 
sekolah berpengaruh terhadap prestasi dan motivasi belajar (Mashud, 2020)(Wafa \& Kusmuriyanto, 2020) (Reny Nurharisma \& Kuswantoro, 2020) (Milta \& Budhi, 2016) (Martina, 2019)(Wulandari, 2020) (Arifin, 2016) (Oktaviana, 2015) (Rahmawati, 2015) (Putriana, 2015) (Oktaviana, 2015) (Nokwanti, 2013)(Sya'diyah \& Fachrurrozie, 2020)(Sya'diyah \& Fachrurrozie, 2020) (Heni Kuswanti, 2020) lingkungan sekolah dan keluarga (Wahid, Setiyoko, Riono, \& Saputra, 2020) dan produktifitas guru (Warsid Warsid, Dekawati, \& Pujiyati, 2020).

\section{METODE}

Kondisi sekolah yang selalu dimasuki ternak dan terkadang masuk ke kelas menjadikan sekolah tidak kondusif untuk belajar. Untuk mengatasi hal ini dilakukan beberapa langkah tindakan. Pertama pengumpulan ide pemecahan masalah dengan melakukan rapat intern guru. Hasil rapat memutuskan untuk melakukan kemunikasi dengan masyarakat yang terdiri dari ketua komite, tokoh masyarakat, tokoh adat, dan juga wali murid, serta seluruh warga dusun Meromo. Hal ini menjadi langkah yang kedua. Ketiga realisasi pertemuan dengan tokok masyarakat terkait untuk musyawarah demi kemajuan pendidikan warga sekitar. Berdasarkan hasil diskusi disepakati beberapa hal. Pertama dibangun pagar dari kayu dibantu warga sebagi penyumbang kayu dan gotong royong membuat pagar. Kedua berkoordinasi dengan warga setempat agar hewan ternak dikandangkan, agar tidak berkeliaran di sekolah.

\section{PELAKSANAAN}

Perlu waktu hampir 1 bulan untuk mengatasi masalah tersebut, adapun langkah-lang kah yang ditempuh untuk mengatasi masalah tersebut adalah: Langkah pertama yang dilakukan adalah rapat dewan guru dan komite, dalam rapat ini kepala sekolah menyampaikan ide dan gagasan mengenai pembuatan pagar sekolah, dan akhirnya disepakati bahwa pembuatan pagar sekolah akan melibatkan wali murid, artinya wali murid yang akan membawa kayu, dan wali murid juga yang akan membuat pagarnya. Setelah terjadi kesepakatan dengan komite, maka sekolah mengundang wali murid untuk rapat di sekolah dengan agenda penyampaian gagasan pembuatan pagar, dan semua wali murid menyetujuinya. Dalam rapat ini di sepakati bahwa pembuatan pagar dilaksanakan satu minggu setelah rapat selesai. Tepat pada waktu yang telah ditentukan wali murid, komite beserta dewan guru bergotong royong membuat pagar sekolah. Setelah pagar selesai, kepala sekolah dan komite berkoordinasi dengan tokoh adat dan tokoh masyarakat setempat untuk memberikan imbauan kepada warga di sekitar sekolah untuk tidak melepaskan binatang ternak.

\section{HASIL PENELITIAN}

Awal pekarangan sekolah dapat dilihat dalam gambar 1 dan gambar 2. Gambar ini memberikan informasi bahwa sekolah memiliki lapangan dan terdapat kubangan, serta rumput yang hijau, sehingga hewan ternak masuk untuk makan rumput yang tumbuh di halaman sekolah. 


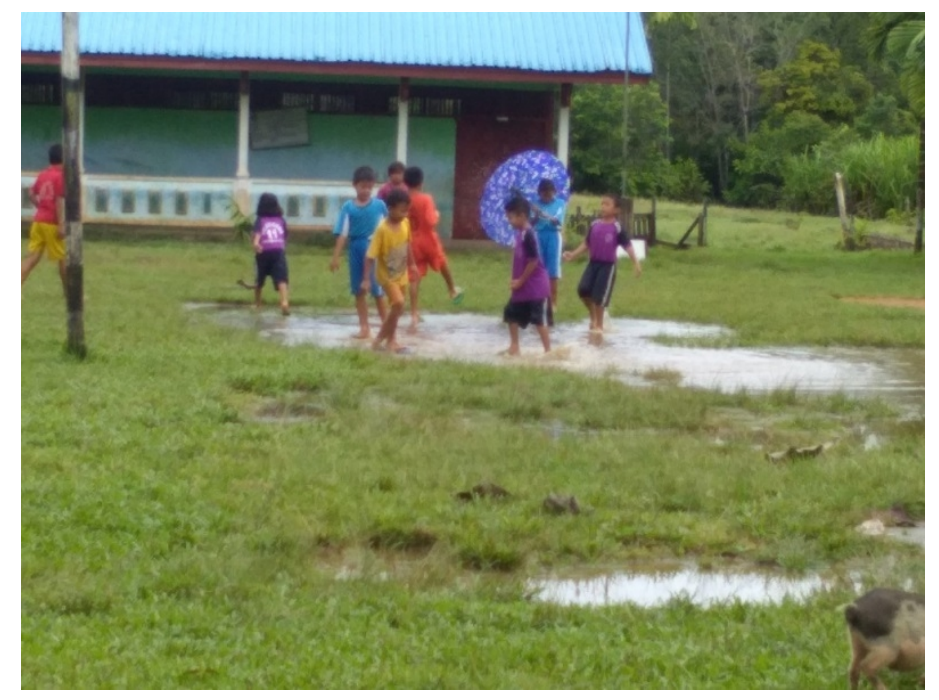

Gambar 1. Kondisi sekolah sebelum dibuatkan pagar

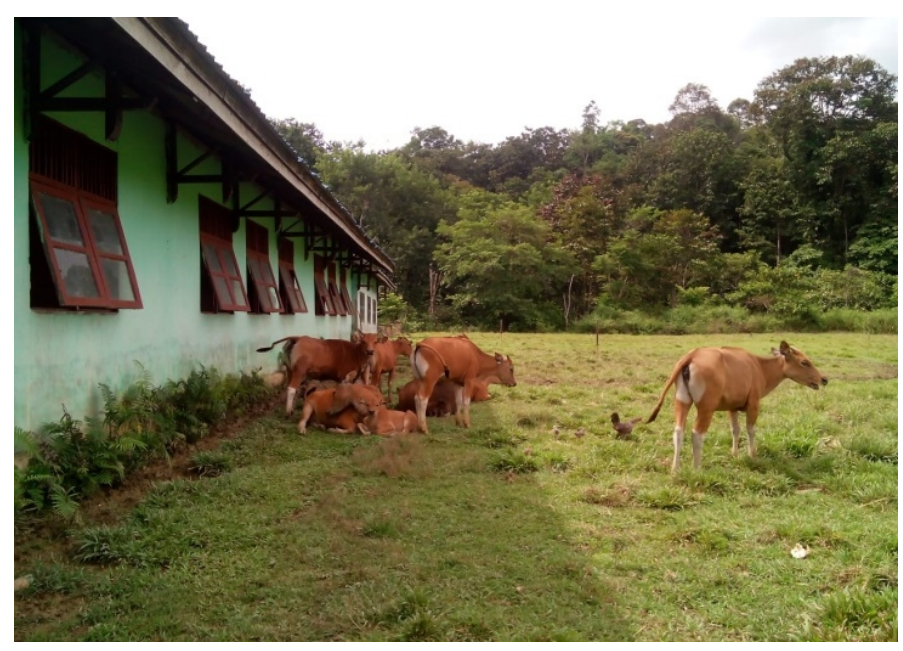

Gambar 2. Sebelum dibuat pagar sapi bebas masuk ke halaman sekolah

Setelah pagar selesai dibuat, binatang ternak tidak lagi masuk ke lingkungan sekolah, sehingga lingkungan sekolah menjadi lebih terlihat bersih, udara menjadi lebih segar, dan peserta didik pun tidak lagi terkena penyakit kulit.

Selain itu praktek muatan lokal budidaya pertanian pun bisa dilaksanakan dengan maksimal, dalam hal ini guru muatan lokal mengembangkan tanaman melon. Tujuan pengembangan melon ini karena melon mempunyai nilai ekonomis yang tinggi, diharapkan nantinya peserta didik setelah selesai sekolah mempunyai keterampilan dalam budidaya melon, sehingga dapat dijadikan salah satu profesi dikemudian hari.

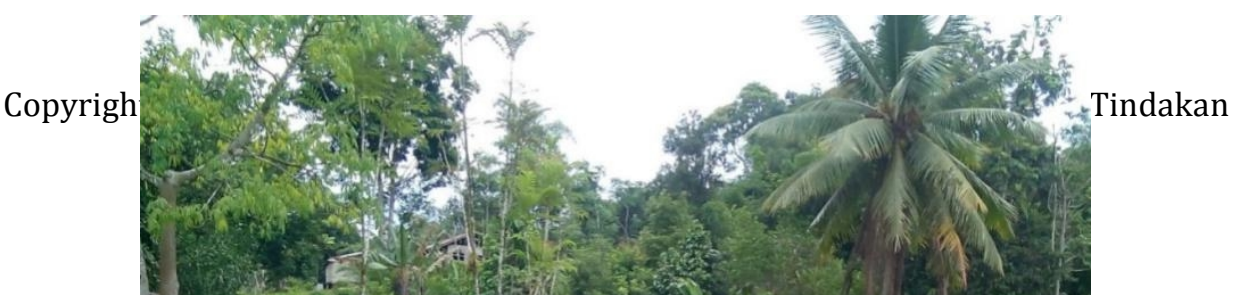


Gambar 3. Pagar yang telah dibuat oleh wali murid

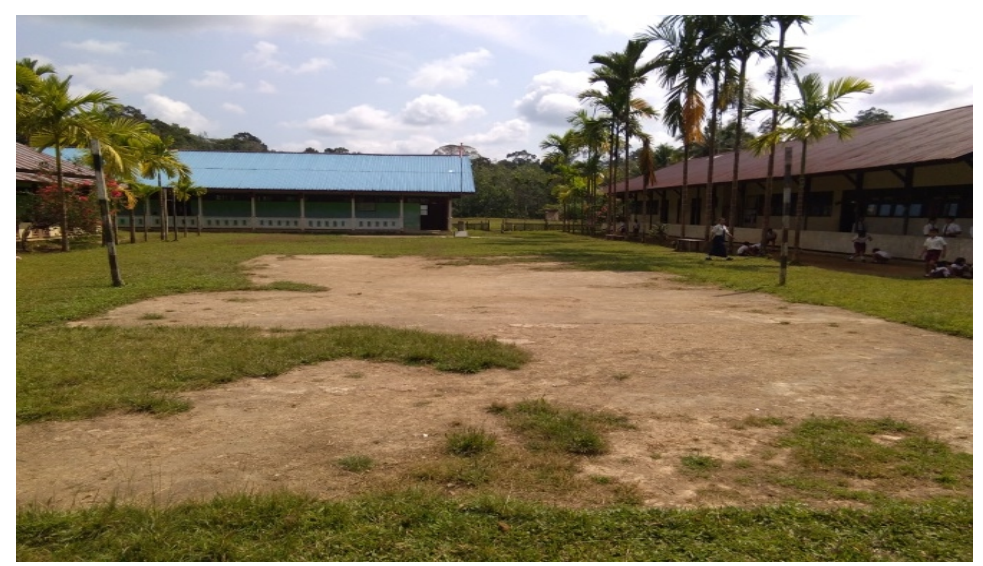

Gambar 4. Suasana sekolah setelah berpagar dan binatang tidak masuk lokasi sekolah

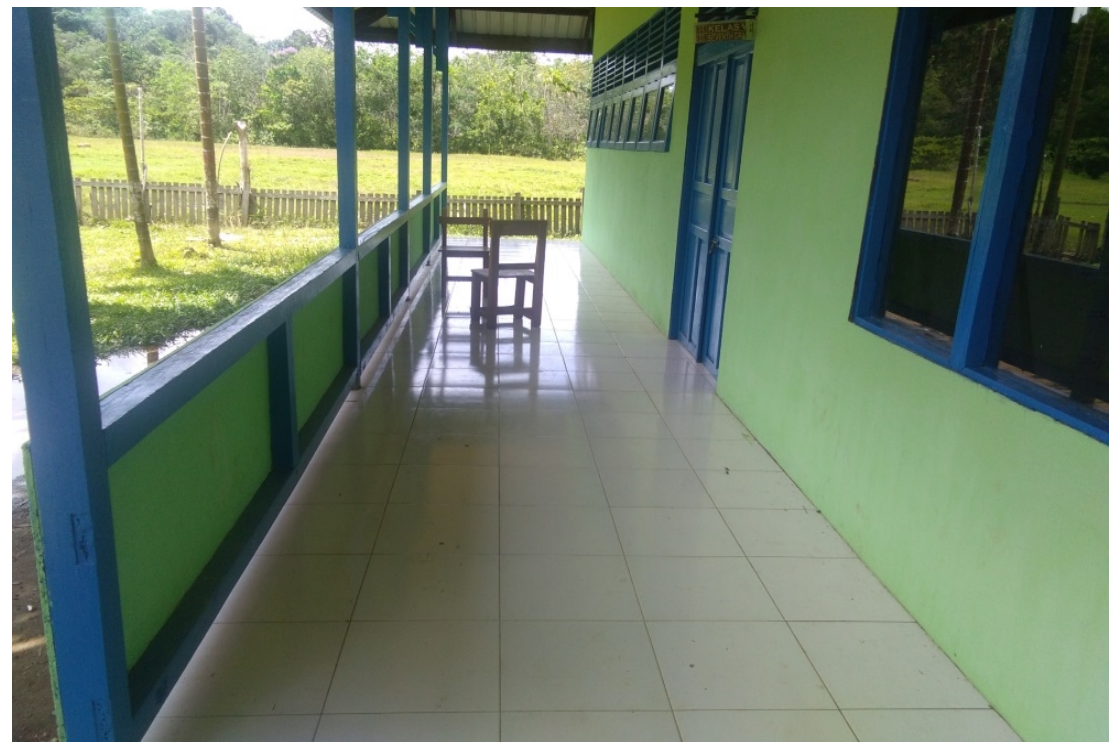

Gambar 5. Foto pagar dari teras sekolah

Penggunaan pagar dari kayu ini mempunyai beberapa kelemahan, diantaranya selain tidak rapi, pagar kayu ini mudah keropos dan tidak tahan lama, sehingga harus sering diganti 
dengan yang baru. Setelah pemagaran selesai dan berkar kerjasama dengan tokok masyarakat, dan kesadaran masyarakat maka hewan ternak tidak lagi di lepas. Kondisi ini memberikan keuntungan dengan lingkungan yang aman dan bersih. Aman yang dimaksud tidak ada lagi hewan herbivora yang berkeliaran merumput di sekitar pekarangan dan kebun sekolah. Kondisi ini membuka peluang untuk memafaatkan kebun sekolah yang terbengkalai. Tanah yang terbengkelai kemudian ditanami dengan buah melon dan ketika sudah mendekati panen ternyata hasilnya cukup menggembirakan seperti dalam gambar 6.
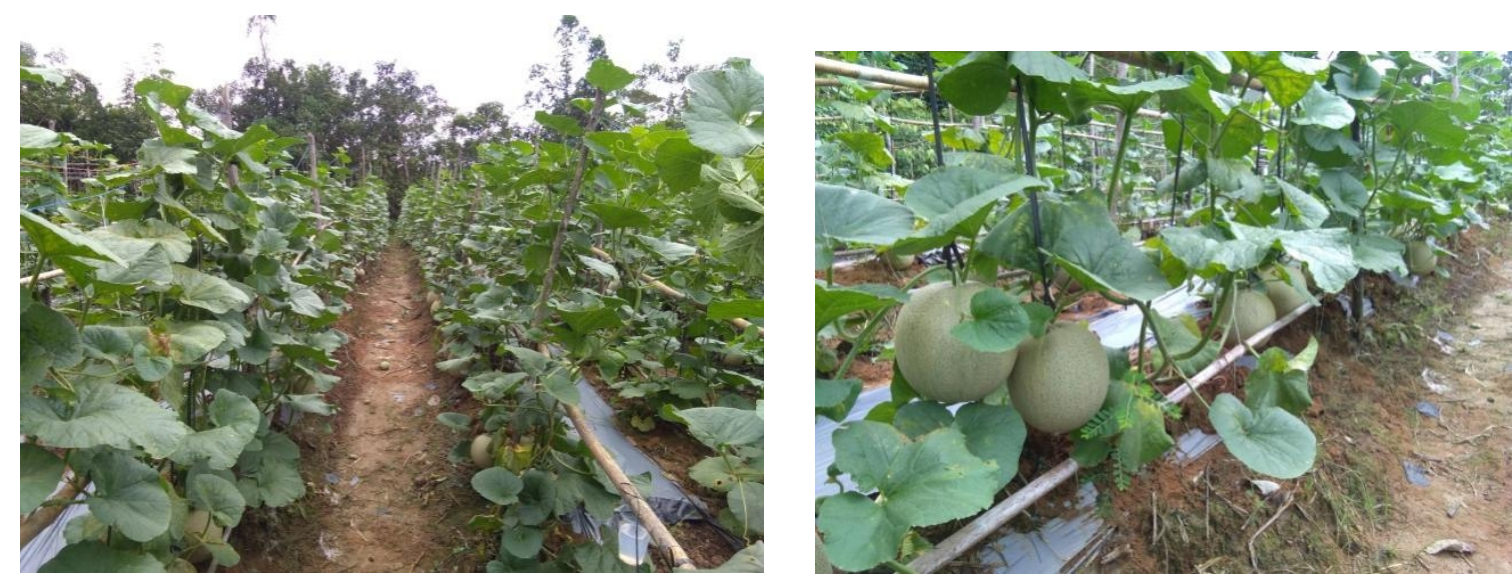

Gambar 6. Hasil pengelolaan lahan kosong sekolah

Setidaknya dengan telah dibangun pagar dan pemanfaatan lahan kosong yang ada, sekolah menjadi lebih baik. Pertama sekolah menjadi lebih bersih, kedua belajar pembelajaran menjadi nyaman, ketiga siswa menjadi lebih bersih karena tidak ada lagi kotoran hewan dan hewan masuk sekolah, keempat ada manfaat ekonomi dengan penanaman lahan kosong sekolah.

Berdasarkan kajian penelitian relevan terdapat dukungan yang besar kondisi sekolah terhadap proses belajar mengajar ataupun etos kerja guru dan siswa. Secara bersama sama lingkungan sekolah dan kompetensi guru berpengaruh terhadap prestasi belajar siswa (Zulaidah \& Widodo, 2020). Peran lingkungan sekolah sangat bersar terhadap prestasi belajar siswa, hal ini disebabkan adanya pemanfaatan lingkungan sebagai sumber belajar (nuraini, ridhwan, \& azwir, 2020). Berdasarkan pada hal ini sangat meyakinkan bahwa lingkungan sekolah harus di desain sebaik mungkin untuk memberikan daya dukung terhadap motivasi dan akhirnya dapat meningkatkan kinerja guru dan siswa. Berdasarkan hasil penelitian dapat diidentifikasi bahwa lingkungan sekolah dapat dipergunakan untuk membantu guru menyampaikan materi pembalajaran dan dapat merangsang kreatifitas siswa (Wahid, Purnomo, \& Ulya, 2020).

Peduli dengan lingkungan dan kampanye untuk mewujudkan sekolah yang nyaman untuk dapat belajar dapat disosialisasikan dengan mengangkat slogan yang mengarah ke perbaikan lingkungan sekolah (Marzuki, Fauziyah, Rahim, \& Sukaris, 2020). Budaya untuk hidup bersih dan sehat di sekolah perlu digiatkan dengan cara sosialisasi hidup bersih dan sehat (Hidayani \& Sugesti, 2020), program ini bertujuan untuk menciptakan lingkungan sekolah yang sehat dan kondusif untuk belajar. Berdasarkan penelitian ternyata lingkungan sekolah berpengaruh terhadap prestasi belajar (Wahid, Setiyoko, et al., 2020). Lingkungan 
sekolah, dan apa yang terjadi di lingkungan sekolah memberikan perespons positif terhadap minat siswa untuk melanjutkan studi lanjut ke perguruan tinggi (Solihat, Nurfitri, \& Nawarini, 2020).

Harapannya dengan usaha yang telah dilakukan dapat memberikan dampak besar terhadap kemajuan pendidikan. Nyatanya kegiatan ini telah mampu untuk membawa masyarakat menyadari arti kebersihan dan pentingnya lingkungan sekolah yang kondusif untuk belajar.

\section{UCAPAN TERIMA KASIH}

Penulis menyampaikan ucapan terima kasih yang sebesar besarnya kepada seluruh warga sekolah SDN 11 Penyeberang Bala, kepada komite, tokoh masyarakat, tokoh adat, dan juga wali murid, serta seluruh warga dusun Meromo, yang telah bahu membahu bekerja sama dalam mewujudkan sekolah yang sehat dan aman.

\section{DAFTAR PUSTAKA}

Aini, M. P. N., Santosa, S., \& Hamidi, N. (2017). Pengaruh Lingkungan Keluarga Dan Lingkungan Sekolah Terhadap Minat Berwirausaha. Pendidikan Akuntansi, FKIP Universitas Sebelas Maret Surakarta, 57126, Indonesia.

Anyau, M. (2018). Pemanfaatan Lingkungan Sekolah Sebagai Media Pembelajaran Biologi. Jurnal Keguruan Dan Ilmu Pendidikan.

Arifin, S. (2016). Hubungan Antara Kondisi Lingkungan Belajar di Sekolah dan Hasil Belajar IPA Siswa Kelas V. Jurnal Pendidikan Guru Sekolah Dasar.

Aristha, L. E. (2019). PENGARUH LINGKUNGAN KELUARGA DAN LINGKUNGAN SEKOLAH TERHADAP KESULITAN BELAJAR SISWA SMA NEGERI 2 SINGARAJA TAHUN PELAJARAN 2016/2017. Jurnal Pendidikan Ekonomi Undiksha.

https://doi.org/10.23887/jjpe.v10i1.20068

Azizah, N. R., Puspikawati, S. I., \& Oktanova, M. A. (2019). INSPEKSI KESEHATAN LINGKUNGAN SEKOLAH DASAR DI KABUPATEN BANYUWANGI. Journal of Public Health Research and Community Health Development. https://doi.org/10.20473/jphrecode.v2i1.16249

Bryan Pudji Hartono. (2018). Hubungan Lingkungan Belajar Di Sekolah Terhadap Hasil Belajar Matematika. JURNAL ILMIAH MATHGRAM Program Studi Matematika.

Fadhilaturrahmi, F. (2017). Lingkungan Belajar Efektif Bagi Siswa Sekolah Dasar. Jurnal Basicedu. https://doi.org/10.31004/basicedu.v1i2.155

Heni Kuswanti, M. (2020). Pengaruh Jaringan Sosial dan Pendidikan Kewirausahaan terhadap Niat Berwirausaha dengan Persepsi Kontrol Perilaku sebagai Variabel Moderasi. Economic Education Analysis Journal.

Herni, Y. (2018). Pengaruh Motivasi Belajar Dan Persepsi Atas Lingkungan Sekolah Terhadap Mata Pelajaran Sejarah Di SMA Al-Hasra Bojongsari Sawangan Depok. JENIUS Uurnal Ilmiah Manajemen Sumber Daya Manusia). https://doi.org/10.32493/jjsdm.v2i1.1941

Hidayani, H., \& Sugesti, R. (2020). Menggiatkan Kegiatan Perilaku Hidup Bersih dan Sehat Di Lingkungan Sekolah Mi Wijaya Kusuma. Jurnal Pengabdian Masyarakat Indonesia Maju. https://doi.org/10.33221/jpmim.v1i01.567 
Hsb, A. A. (2018). KONTRIBUSI LINGKUNGAN BELAJAR DAN PROSES PEMBELAJARAN TERHADAP PRESTASI BELAJAR SISWA DI SEKOLAH. JURNAL TARBIYAH. https://doi.org/10.30829/tar.v25i2.365

Martina. (2019). Pengaruh Lingkungan Sekolah Terhadap Hasil Belajar Siswa pada Mata Pealajaran Pendidikan Agama Islam di SMP Negeri 9 TULUNG Selapan Kabupaten Oki. Jurnal PAI Raden Patah.

Marzuki, I., Fauziyah, N., Rahim, A. R., \& Sukaris, S. (2020). SLOGAN PEDULI LINGKUNGAN SEKOLAH. DedikasiMU(Journal of Community Service). https://doi.org/10.30587/dedikasimu.v2i4.2061

Mashud, M. (2015). Pendekatan Pembelajaran Pendidikan Jasmani Olahraga dan Kesehatan di Era Abad 21. Jurnal Multilateral, 14(2), 89-196. https://doi.org/10.20527/multilateral.v14i2.2471.g2172

Mashud, M. (2020). The Effectiveness of Physical Education Learning in Elementary School Located in Wetland Environment. Jurnal Pendidikan: Teori, Penelitian, Dan Pengembangan, 5(2), 265-270. https://doi.org/DOI: http://dx.doi.org/10.17977/jptpp.v5i2.13194

Milta, N., \& Budhi, W. (2016). Hubungan Antara Minat Belajar Siswa, Kemampuan Awal Dan Lingkungan Sekolah Dengan Prestasi Belajar. Jurnal Ilmiah Pendidikan Fisika.

Munawar, S., Heryanti, E., \& Miarsyah, M. (2019). HUBUNGAN PENGETAHUAN LINGKUNGAN HIDUP DENGAN KESADARAN LINGKUNGAN PADA SISWA SEKOLAH ADIWIYATA. LENSA (Lentera Sains): Jurnal Pendidikan IPA. https://doi.org/10.24929/lensa.v1i1.58

Nazir, A. (2019). Pengaruh Lingkungan Sekolah terhadap Motivasi Warga Belajar pada (Pusat Kegiatan Belajar Masyarakat) PKBM Cipta Tunas Karya. Jurnal Mandiri : Ilmu Pengetahuan, Seni, Dan Teknologi. https://doi.org/10.33753/mandiri.v3i2.88

Nokwanti. (2013). Pengaruh Tingkat Disiplin Dan Lingkungan Belajar Di Sekolah Terhadap Prestasi Belajar Siswa. Jurnal Pendidikan Ekonomi IKIP Veteran Semarang.

Nuraini, N., Ridhwan, M., \& Azwir, A. (2020). PENGARUH PEMANFAATAN LINGKUNGAN SEKOLAH TERHADAP PENINGKATAN HASIL BELAJAR SISWA PADA MATERI AJAR INTERAKSI MAKHLUK HIDUP DENGAN LINGKUNGAN DI SMP NEGERI 2 MESJID RAYA KABUPATEN ACEH BESAR. Jurnal Biology Education. https://doi.org/10.32672/jbe.v8i2.2367

Oktaviana, I. (2015). Pengaruh Lingkungan Sekolah terhadap motivasi belajar siswa kelas V Sekolah Dasar di daerah Binaan I Kecamatan Limpung Kabupaten Batang. Universitas Negeri Semarang.

Putriana, N. (2015). PENGARUH LINGKUNGAN KELUARGA DAN LINGKUNGAN SEKOLAH TERHADAP PRESTASI BELAJAR SISWA PADA MATA PELAJARAN AKUNTANSI DI KELAS XI IPS SMA PASUNDAN 8 BANDUNG. JURNAL PENDIDIKAN AKUNTANSI \& KEUANGAN. https://doi.org/10.17509/jpak.v3i1.15383

Rahmawati, Y. (2015). Pengaruh Kondisi Ekonomi Orang Tua, Lingkungan Sekolah, Dan Prestasi Belajar Terhadap Minat Melanjutkan Pendidikan Tinggi. JPEKA: Jurnal Pendidikan Ekonomi, Manajemen Dan Keuangan.

Reny Nurharisma, E., \& Kuswantoro, A. (2020). Perencanaan Program Praktik Kerja Lapangan di SMK Negeri 2 Jepara. Economic Education Analysis Journal. 
Rosyad, A. M. (2019). Implementasi Pendidikan Karakter Melalui Kegiatan Pembelajaran Di Lingkungan Sekolah. Tarbawi: Jurnal Keilmuan Manajemen Pendidikan.

Solihat, S., Nurfitri, T., \& Nawarini, A. T. (2020). PENGARUH POTENSI DIRI, LINGKUNGAN SEKOLAH DAN TINGKAT PENDIDIKAN ORANG TUA TERHADAP MINAT SISWA MELANJUTKAN STUDI KE PERGURUAN TINGGI DI MAN 1 BANYUMAS. Soedirman Economics Education Journal. https://doi.org/10.32424/seej.v2i2.3001

Suardi, Akib, H., \& Tamsah, H. (2016). Pengaruh Kepemimpinan, Budaya Dan Lingkungan Sekolah Terhadap Kinerja Guru Dalam Pembelajaran Pada Sdit Al-Fityan School Kabupaten Gowa. Jurnal Mirai Management.

Sya'diyah, N., \& Fachrurrozie. (2020). Pengaruh lingkungan Teman Sebaya dan Perencanaan Karir terhadap Minat Melanjutkan Pendidikan dengan Motivasi Belajar sebagai Variabel Mediasi Nurhalimatusy Sya'diyah. Economic Education Analysis Journal.

Wafa, M. A., \& Kusmuriyanto. (2020). Peran Praktik Pengalaman Lapangan dalam Memediasi Pengaruh Self Efficacy dan Penguasaan MKDK terhadap Kesiapan Menjadi Guru. Economic Education Analysis Journal.

Wahid, F. S., Purnomo, M. A., \& Ulya, S. M. (2020). Analisis Peran Guru Dalam Pemanfaatan Lingkungan Sekolah Terhadap Kreativitas Belajar Siswa. Jurnal Ilmiah KONTEKSTUAL. https://doi.org/10.46772/kontekstual.v2i01.247

Wahid, F. S., Setiyoko, D. T., Riono, S. B., \& Saputra, A. A. (2020). Pengaruh Lingkungan Keluarga Dan Lingkungan Sekolah Terhadap Prestasi Belajar Siswa. Syntax Literate ; Jurnal Ilmiah Indonesia. https://doi.org/10.36418/syntax-literate.v5i8.1526

Warsid Warsid, Dekawati, I., \& Pujiyati, W. (2020). ANALISIS KONDISI LINGKUNGAN SEKOLAH DAN MOTIVASI BERPRESTASI SERTA DAMPAKNYA TERHADAP PRODUKTIVITAS KERJA GURU. Edum Journal. https://doi.org/10.31943/edumjournal.v3i2.68

Wati, A. K., \& Muhsin. (2019). Pengaruh Minat Belajar, Motivasi Belajar, Lingkungan Keluarga, dan Lingkungan Sekolah Terhadap Kesulitan Belajar. Economic Education Analysis Journal.

Wulandari, F. (2020). PEMANFAATAN LINGKUNGAN SEBAGAI SUMBER BELAJAR ANAK SEKOLAH DASAR. Journal of Educational Review and Research. https://doi.org/10.26737/jerr.v3i2.2158

Zulaidah, R., \& Widodo, J. (2020). Penanaman Sikap Kewirausahaan Melalui Praktik Kejuruan Produk Kreatif dan Kewirausahaan. Economic Education Analysis Journal. 